Rachel de Aquino Câmara ${ }^{1}$

Regina Heloisa Maciel ${ }^{2}$

Rosemary Cavalcante Gonçalves ${ }^{2}$

\section{Prevenção e combate ao assédio moral entre servidores públicos do estado do Ceará}

\author{
Prevention of bullying at work in a public organization of the \\ State of Ceará, Brazil
}

${ }^{1}$ Bolsista de Iniciação Científica do CNPq. Laboratório de Estudos do Trabalho (LET), Programa de PósGraduação em Psicologia, Centro de Ciências Humanas, Universidade de Fortaleza. Fortaleza, CE, Brasil.

${ }^{2}$ Orientadoras do Projeto de Prevenção e Combate ao Assédio Moral dos Servidores Públicos da Administração Direta do Estado do Ceará. Membros da Comissão Permanente de Prevenção e Combate ao Assédio Moral do Estado do Ceará. Laboratório de Estudos do Trabalho (LET), Programa de PósGraduação em Psicologia, Centro de Ciências Humanas, Universidade de Fortaleza. Fortaleza, CE, Brasil.

A pesquisa recebeu subvenção do Conselho Nacional de Desenvolvimento Científico e Tecnológico (CNPq) na forma de Bolsa de Iniciação Científica para a primeira autora pelo Programa de IC da Universidade de Fortaleza (Unifor).

Não há conflitos de interesse. Tanto o projeto, quanto a pesquisa receberam a aprovação da Secretaria de Planejamento e Gestão do Estado do Ceará (Seplag) e a pesquisa recebeu aprovação do Comitê de Ética em Pesquisa em Seres Humanos (Coética) da Unifor.

O trabalho foi apresentado no $7^{\circ}$ Congresso Norte-Nordeste de Psicologia, em 2011, na forma de resumo.

Contato:

Regina Heloisa Maciel

E-mail:

reginaheloisamaciel@gmail.com

\section{Resumo}

O assédio moral, violência moral ou psicoterrorismo no trabalho é um tema que vem sendo bastante discutido nas últimas décadas, incorporando-se aos estudos na área de saúde do trabalhador. A fim de incentivar estudos sobre o conceito e favorecer a prevenção e o combate de tal fenômeno entre os servidores públicos do Ceará, bem como proporcionar condições de trabalho favoráveis à saúde do trabalhador, foi instituido em 2009 um projeto de prevenção e combate ao assédio moral na administração pública executiva do estado. Este artigo relata a instalação da primeira Comissão Setorial de Combate ao Assédio Moral no Trabalho, do treinamento desta para intervir em situações de assédio e da avaliação do processo de capacitação e sua adequação à proposta do projeto. O treinamento do grupo constituiu de reuniões quinzenais durante cinco meses e com visitas em algumas unidades de uma das secretarias do estado. Para a avaliação desse processo foram realizadas entrevistas semiestruturadas com os integrantes, após o treinamento, em 2010. Apesar dos resultados mostrarem que o grupo teve algumas dificuldades de envolvimento com a proposta, eles apresentaram um maior discernimento acerca do que é ou não um caso fidedigno de assédio moral e acerca da postura a ser adotada nos casos de assédio.

Palavras-chave: assédio moral; administração pública; saúde do trabalhador; ambiente de trabalho.

\section{Abstract}

Bullying at work is a theme that has been widely discussed in recent decades, adding to the topics studied in the occupational health area. A project to prevent and control bullying in public administration was implemented in 2009, with the purpose of encouraging studies on the concept of this phenomenon, and promoting its prevention and control, as well as providing healthier working conditions among civil servants in Ceará state, Brazil. This article reports on the establishment of the first Committee for the Prevention of Bullying at Work, the training of a team of civil servants to intervene in bullying situations, and on the assessment of this training. The training lasted five months, with meetings every two weeks as well as visits to units of one of the state secretaries. At the end of the process in 2010, the training and its appropriateness to the project proposal was assessed by semi-structured interviews conducted with members of the team. Although results showed that team members were not totally committed to the proposal, after training they had a better undestanding and were more prepared to act in cases of bullying at work.

Keywords: bullying at work, public administration, worker health, work environment. 


\section{Introdução}

O assédio moral ou violência moral é um tema que vem sendo bastante discutido nas últimas décadas, incorporando-se aos estudos da área de saúde do trabalhador. O fenômeno é definido como toda exposição prolongada e repetitiva a situações humilhantes e vexatórias dos trabalhadores no desempenho de suas funções, gerando sofrimento psíquico e degradação do ambiente de trabalho (BARRETO, 2003). O assédio moral no trabalho divide-se em duas grandes categorias: o pessoal, ligado às questões das relações interpessoais; e o da organização do trabalho, ligado especificamente às questões do contexto, do processo e da gestão do trabalho (BESWICK; GORE; PALFERMAN, 2006). Ademais, o assédio moral pode ocorrer de forma vertical ou horizontal, isto é, refere-se tanto a relações hierárquicas entre chefe e subordinado como entre trabalhadores de mesmo nível.

O assédio moral não é um fenômeno novo, mas a mudança de foco de uma perspectiva coletiva para uma mais individualista, no que se refere à cultura, tem contribuído para uma maior visibilidade de sua ocorrência e consequências (AGERVOLD, 2007). As raízes da ocorrência do assédio podem estar no que Sennett (2006) descreve como a "cultura do novo capitalismo". Segundo o autor, o espaço social das organizações é permeado, atualmente, pelo individualismo, pela incerteza e pela falta de responsabilidade nas relações sociais. Assim, embora o autor não se refira diretamente à questão, pode-se deduzir que as mudanças impostas pela reestruturação produtiva faz com que o espaço social das organizações adquira contornos que podem levar aos fatores normalmente descritos como determinantes da violência moral no trabalho.

O assédio tem sido descrito em vários contextos de trabalho, incluindo as organizações públicas. Segundo Caran et al. (2010), o assédio ocorre com maior frequência em instituições caracterizadas por hierarquias e procedimentos rígidos, nos quais as tarefas não são definidas, sendo possível culpar alguém por alguma coisa. A autora afirma que, no setor privado, o assédio moral é mais evidente, dura menos tempo e termina geralmente com a saída da vítima. Em contrapartida, no setor público, ele pode durar anos, pois as pessoas são protegidas pela organização, o que contribui para que as situações de assédio não sejam averiguadas de maneira adequada em decorrência do grau de parentesco e das relações de amizade existentes. Além disso, as práticas de assédio não buscam acarretar a demissão do funcionário, visto tratar-se de uma organização pública. O intuito é denegrir sua imagem, causar seu sofrimento no ambiente de trabalho ou favorecer sua transferência para outro setor, o que pode gerar insatisfação e ansiedade (BATALHA, 2009).
As recomendações para o combate e a prevenção do assédio envolvem dois níveis de intervenção: legislativo e administrativo. Intervenções baseadas apenas na legislação ou em normas são consideradas pouco satisfatórias. Como afirma o relatório da Força Tarefa para Prevenção do Assédio no Trabalho, constituída pelo Ministério do Trabalho da Irlanda, o assédio é uma questão que deve ser resolvida no nível da empresa, por meio da "autorregulação" daqueles diretamente envolvidos em oposição a intervenções no nível estatal ou governamental (TASK FORCE ON THE PREVENTION OF WORKPLACE BULLYING, 2001). Assim também, Tehrani (2007) acredita que a prevenção do assédio vai muito além da existência de uma legislação específica acerca do assunto, devendo envolver a criação de comissões internas para sua mediação e investigação. No entanto, Verry (2008), embora reconhecendo a importância de ações proativas na resolução do assédio no trabalho, advoga pela necessidade de normas internas e legislação na medida em que as práticas no trabalho e as relações de trabalho podem ser encorajadas, resistir ou serem redirecionadas pela legislação.

Intervenções baseadas em treinamentos gerais, como uma forma de diminuir a ocorrência do assédio, foram realizadas em diferentes contextos e países, envolvendo grupos de trabalhadores e gerentes (ALTMAN, 2009). Hoel e Giga (2006) conduziram um estudo no setor público inglês testando a viabilidade de vários tipos de treinamento envolvendo política de comunicação, gerenciamento do estresse e conscientização de comportamentos negativos no trabalho. Os resultados mostraram que a efetividade do treinamento depende do contexto de trabalho e que ações mais eficazes e complexas devem ser realizadas no sentido de prevenir a ocorrência do assédio nas organizações. Além disso, Altman (2009) considera que treinamentos gerais envolvendo o desenvolvimento de habilidades da vítima no trato do assédio tendem a ser pouco efetivos, principalmente quando a vítima já se encontra fragilizada ou apresenta problemas psicológicos.

Intervenções baseadas em ações administrativas proativas, como a criação de comissões para mediação e investigação do assédio acompanhadas da possibilidade de punição para os assediadores, têm sido recomendadas e parecem ter tido sucesso no combate e na prevenção do assédio. Pate e Beaumont (2010) descrevem um estudo de caso de uma empresa estatal inglesa que implementou um programa de "Dignidade no Trabalho", similar ao proposto para a administração direta do estado do Ceará. Segundo os autores, o programa foi efetivo na diminuição de relatos de que as pessoas foram afetadas por assédio moral, embora ele não tenha melhorado a confiança dos trabalhadores nos gerentes da instituição. Meglich-Sespico, 
Faley e Knapp (2007) acreditam que a melhor estratégia envolve tanto intervenções organizacionais para prevenir e resolver os incidentes de assédio, quanto mecanismos legislativos fortes que permitam a compensação e a recomposição das vítimas.

Maciel e Gonçalves (2007) realizaram um estudo sobre o assédio moral entre os trabalhadores da administração do estado do Ceará. Para medir a ocorrência do assédio, foi utilizado o instrumento proposto por Einarsen e Hoel (2001) cuja validação encontra-se descrita em Maciel e Gonçalves (2008). A amostra foi composta por 147 trabalhadores que compareceram a reuniões promovidas pelos sindicatos da categoria, tratando-se, portanto, de uma amostra não probabilística. Os resultados mostraram que 38\% dos servidores entrevistados foi alvo de comportamentos negativos, considerados de assédio moral, com frequência semanal ou diária nos seis meses precedentes. Esses resultados foram importantes para subsidiar os sindicatos, representados pela Associação dos Funcionários e Servidores Públicos do Estado do Ceará (Afuaspec), na apresentação da questão do assédio moral como pauta de negociação coletiva em 2008, o que resultou em uma série de ações voltadas para a construção de um programa de prevenção e combate ao assédio moral. Foi criada uma Comissão Permanente de Combate ao Assédio Moral composta por representantes da Secretaria de Planejamento e Gestão, da Secretaria de Controladoria e Ouvidoria, do Centro de Referência em Saúde do Trabalhador da Secretaria da Saúde do Estado (Cerest) e representantes da Afuaspec. Essa comissão foi responsável pela elaboração e o desenvolvimento do projeto final, que envolve a criação de comissões bipartites, representantes da gestão e dos trabalhadores nos órgãos da administração direta, denominadas de Comissões Setoriais de Combate ao Assédio Moral no Trabalho (CS). As CS ficam subordinadas à comissão permanente, que tem por função orientar, capacitar e acompanhar suas atividades.

O projeto tem por objetivo promover a dignidade dos servidores e empregados e prevenir a ocorrência do assédio moral nos órgãos da administração direta do estado. Entre as ações já desenvolvidas estão: implantação de uma CS como projeto piloto, realização de seminários para informação e sensibilização dos servidores, elaboração do Manual de prevenção e combate do assédio moral na administração pública (CEARÁ [Estado], 2010) e a aprovação pela Assembleia Legislativa do Estado da Lei no ${ }^{2} 15.036$ (CEARÁ [Estado], 2011) de combate ao assédio.

As ações propostas seguem as recomendações encontradas na literatura sobre o assunto, como, por exemplo, a Política de Dignidade no Trabalho do Instituto de Tecnologia de Dublin (DUBLIN INSTITUTE OF TECHNOLOGY, 2007), os procedimentos adotados pela Organização Panamericana de Saúde
(OPAS) para prevenção e resolução do assédio moral no trabalho (ORGANIZAÇÃO PANAMERICANA DE SAÚDE, 2004), os recomendados pela Força-Tarefa de Prevenção do Assédio no Trabalho do governo irlandês (TASK FORCE ON THE PREVENTION OF WORKPLACE BULLYING, 2001) e os passos propostos por Tehrani (2007).

A definição de assédio moral que norteia os trabalhos das comissões, constante do Manual de prevenção e combate ao assédio moral na administração pública (CEARÁ [Estado], 2010, p. 7), afirma:

\begin{abstract}
"Assédio moral é qualquer conduta abusiva (gesto, palavra, comportamento, atitude) que atente, por sua repetição ou sistematização, contra a dignidade ou integridade psíquica ou física de uma pessoa, ameaçando seu emprego ou degradando o clima de trabalho" (Hirigoyen, 2002, p. 17). As condutas abusivas são consideradas indesejáveis pela vítima e envolvem situações em que a mesma tem dificuldades para se defender. O intuito é levar à desestabilização psíquica ou ao afastamento da vítima do local de trabalho.
\end{abstract}

Ressalta-se que o projeto ainda está em fase de implantação, o que justifica a necessidade de avaliar os resultados das ações iniciais com a finalidade de correções e adequações no processo. Este artigo refere-se à implantação da primeira CS em uma das secretarias do estado. A escolha do local para o desenvolvimento do projeto piloto de CS foi realizada de forma consensual pela comissão permanente, pois havia, na ocasião, indicativos de que a secretaria escolhida apresentava um grande número de queixas de assédio moral.

O objetivo deste trabalho é descrever as medidas adotadas e colocadas em prática na implantação da primeira Comissão de Combate e Prevenção ao Assédio Moral e avaliar o processo de capacitação efetuado.

\section{Método}

Esta pesquisa, realizada em 2010, é de natureza qualitativa, tipo estudo de caso, composta por análise documental e cinco entrevistas individuais com o total de componentes da CS piloto do "Projeto de Prevenção e Combate ao Assédio Moral dos Servidores Públicos da Administração Direta do Estado do Ceará".

Inicialmente, as propostas do projeto passaram por análise documental, enfatizando as ações realizadas no que se refere à implantação da primeira CS. Para tal, os documentos foram analisados a fim de se compreender os objetivos da implantação e as ações efetivamente realizadas. As principais decisões dessa etapa são descritas a seguir. 
Com o intuito de avaliar a efetividade do processo de formação e capacitação da primeira CS, foi realizada uma pesquisa junto aos seus membros. Os cinco participantes da comissão foram entrevistados individualmente após um ano de sua nomeação. $\mathrm{Na}$ análise dos discursos, optou-se por utilizar números para identificar os entrevistados, sendo que S1 a S3 são representantes da gerência e S4 e S5, representantes dos servidores.

As entrevistas foram analisadas utilizando-se a metodologia proposta por Lefevre e Lefevre (2011): Discurso do Sujeito Coletivo. Esse método é constituído por três etapas complementares: a identificação das ideias centrais presentes nas falas dos sujeitos entrevistados; a transcrição literal de trechos de entrevistas que representam expressões-chave de mesmo sentido; e o discurso do sujeito coletivo propriamente dito, que agrega e sintetiza, em um discurso, redigido na primeira pessoa do singular, os distintos conteúdos e argumentos individuais de sentido semelhante, compondo, assim, um depoimento coletivo.

As entrevistas foram realizadas no próprio local de trabalho, mas em salas isoladas, permitindo uma conversa franca e aberta sobre as opinióes dos entrevistados a respeito de sua participação na CS e sobre a possível efetividade desse trabalho na prevenção e no combate ao assédio moral na secretaria em questão.

Das entrevistas semiestruturadas constavam perguntas tais como: "Como você descreveria o seu grupo?", "Que fatores tendem a facilitar a eficiência de seu trabalho na comissão?", "Que fatores tendem a diminuir ou inibir a eficiência de seu trabalho na comissão?", "Quais os problemas mais importantes que ainda não foram resolvidos pelo grupo?", "O que funciona bem no grupo?", "Que empecilhos você vê para efetuar o Projeto de Prevenção e Combate ao Assédio Moral?". Todas as entrevistas foram gravadas e posteriormente transcritas na íntegra.

O processo como um todo recebeu a aprovação dos órgãos do governo responsáveis pelo projeto e do Comitê de Ética da Universidade de Fortaleza. Antes da realização das entrevistas, os participantes foram informados sobre seus objetivos e assinaram um Termo de Consentimento Livre e Esclarecido (TCLE).

\section{Resultados e discussão}

\section{Análise documental}

No intuito de contribuir para uma atuação mais dirigida e eficaz dos gestores e trabalhadores do serviço público executivo do estado do Ceará, bem como de suas representações (associações, sindicatos, federações, controle social etc.), foi elaborado pela comissão permanente um Manual de prevenção e combate ao assédio moral na administração pública (CEARÁ [Estado], 2010) para uso das comissões setoriais. Nele constam as medidas que devem ser adotadas desde o recebimento da queixa de assédio moral até procedimentos de investigação e mediação entre denunciado e denunciante. A seguir são descritas sucintamente as etapas descritas no Manual.

\section{Queixa}

A queixa poderá ser feita por qualquer trabalhador que está sendo vítima de assédio moral no seu ambiente de trabalho, qualquer trabalhador que esteja testemunhando o assédio moral no local de trabalho ou por representações de trabalhadores, como associações e sindicatos, que tenham recebido uma denúncia. A queixa é realizada, por meio escrito ou verbal, em um prazo de até seis meses corridos a partir da data do suposto assédio. Cabe a um membro da CS receber a queixa, entrevistar o denunciante e levantar informações consubstanciadas em um Formulário de Queixa. No formulário, constam dados referentes ao denunciado e ao denunciante e a narração dos fatos. Esse documento torna-se confidencial e somente os membros da CS têm acesso a ele.

\section{Indicação de relator e investigação no local de trabalho}

Após o recebimento da queixa, o coordenador da CS indica um relator do processo: um dos membros da própria comissão. O relator investiga e analisa a queixa, podendo para isso compor um grupo de trabalho com outros membros da CS e/ou da comissão permanente, bem como outros técnicos, tais como profissionais do Cerest. A investigação consiste no estudo do local de trabalho de onde partiu a queixa no intuito de obter mais informações e esclarecer situações, buscando coletar evidências de que os fatos relatados ocorreram e confirmar se a queixa, de fato, corresponde à definição de assédio moral. O método investigativo compreende observações e entrevistas no local de trabalho e/ou em outros locais agendados com os entrevistados.

Para efeito da investigação, é utilizado o Formulário de Entrevista Individual com perguntas abertas que devem ser feitas por meio de entrevistas com os trabalhadores durante a visita, sendo-lhes assegurada a confidencialidade das informações. Dentre as perguntas, destacam-se as seguintes: "O que você acha dos relacionamentos entre as pessoas do setor?", "O que você acha da chefia deste setor?", "O que você acha do clima de trabalho neste setor?", "Você já presenciou alguma desavença aqui no setor?”, "Qual o motivo da desavença?", "Você já presenciou alguém sendo 'assediado' no setor? Descreva”.

A CS pode solicitar documentos ou informações que venham a esclarecer o assunto. Para tan- 
to, os superiores hierárquicos devem colaborar com a CS quando solicitados, com a finalidade de se obter todos os elementos necessários para concluir a investigação.

\section{Contato com o denunciado}

Após a investigação, no caso da CS achar que a queixa pode se constituir em assédio moral, o relator envia notificação de recebimento da queixa de assédio ao denunciado, com agendamento de data para entrevista. O denunciado deve comparecer à entrevista ou justificar a ausência, solicitando remarcação da data. Caso não compareça, suas ausências, justificadas ou não, devem fazer parte do relatório. $\mathrm{O}$ relato do denunciado, durante a entrevista, deve ser redigido pelo relator e assinado depois da leitura e concordância com os termos escritos. O denunciado pode, se desejar, não participar da entrevista e apresentar sua resposta por escrito à CS dentro de prazo especificado, que não exceda 15 dias, a contar da data em que recebeu a notificação.

\section{Parecer, relatório e ações}

Cabe ao relator fazer a síntese das informações coletadas na investigação e, junto com os dados levantados no Formulário de Queixa e no relato do denunciado, apresentar seu Parecer Consubstanciado à CS. O parecer é apresentado pelo relator em reunião e, após a discussão, é tomada a decisão final sobre a ocorrência ou não do assédio moral.

No caso de confirmação da ocorrência de assédio moral, o denunciante é consultado sobre a decisão de dar continuidade ao processo com solicitação de abertura de Sindicância (Processo Administrativo). Havendo o consentimento pelo denunciante, o parecer é encaminhado ao Setor de Recursos Humanos ou setor com função similar para que seja aberta sindicância em um prazo máximo de 30 dias. A abertura de sindicância e o procedimento disciplinar administrativo não são da competência da CS e seguem os trâmites dispostos no Estatuto do Servidor Público do Estado.

Entretanto, antes de se encaminhar o parecer ao Setor de Recursos Humanos ou Setor Administrativo/Jurídico para abertura do Processo Disciplinar Administrativo, a CS pode propor às partes envolvidas a alternativa de mediação ou conciliação. $\mathrm{O}$ objetivo da mediação é tentar resolver a questão com menos desgaste de ambas as partes e evitar o recurso de procedimentos formais administrativos. Se a mediação for satisfatória, o comportamento que originou a queixa poderá cessar e o padrão normal de trabalho, restaurado. Se a CS achar conveniente, pode convidar um mediador externo para realização desse procedimento. O papel do mediador é assistir às partes na negociação, de forma imparcial, focando na busca de soluções e não nas situações passadas que geraram o problema.

No caso da não confirmação de assédio moral, a CS deve expor no parecer que a queixa é improcedente. Contudo, pode ainda sugerir outros meios de solucionar o problema (por exemplo, treinamento, reorganização do trabalho, mediação etc.) e orientar as partes envolvidas. Vale salientar que, mesmo quando a denúncia não é confirmada, em nenhum caso são tomadas medidas contra o denunciante. Ao invés disso, deve ser dada especial atenção à situação para assegurar que o assédio moral não venha a ocorrer, uma vez que se trata de uma comissão voltada não somente para o combate, mas também para a prevenção de assédio moral.

O processo finaliza com a apresentação do parecer no prazo máximo de 45 dias após a formalização da queixa. Esse prazo pode ser prorrogado por mais 45 dias, desde que com justificativa aceitável. As informações que constam do parecer são: resumo dos principais fatos do caso que foram comprovados pela CS; resumo das visitas e das entrevistas realizadas; resumo dos argumentos expostos pelo denunciante e pelo denunciado; decisão tomada pela CS, confirmando ou não o assédio moral, e sua fundamentação; e as recomendações para contribuir na solução do problema. A CS comunica sua resposta aos envolvidos em um prazo de até 10 dias a partir do término do processo.

Outra ação prevista é o encaminhamento do denunciado, mesmo antes da investigação e finalização do processo, a atendimento psicológico e/ ou médico e seu acompanhamento. Considera-se importante que a vítima tenha acesso a esse tipo de atendimento o mais rápido possível, tendo em vista as consequências do assédio moral sobre a saúde física e mental das vítimas.

Além disso, se alguns dos fatos percebidos durante as visitas e as entrevistas não se caracterizam como assédio, mas podem estar contribuindo para a sua ocorrência ou se constituir em um perigoso precedente, a CS pode encaminhar denúncia formal aos setores competentes ou ao sindicato.

\section{Processo de formação da CS estudada}

Buscando capacitar os membros da CS piloto na realização dos procedimentos descritos acima, foram feitas reuniões quinzenais de março a julho de 2010, com discussões sobre o que é assédio moral, suas possíveis causas e consequências; as atribuições e os deveres das comissões permanente e setorial; a apresentação do Manual, do formulário de queixa, do registro de entrevista individual de investigação e dos procedimentos referentes à mediação entre as 
partes envolvidas. Ademais, ocorreram visitas em alguns órgãos da secretaria pelos membros da CS acompanhados pelos instrutores, durante as quais foram realizadas entrevistas semiestruturadas com alguns servidores públicos estatutários ou terceirizados baseando-se nas perguntas presentes no formulário de entrevista individual do Manual.

Após a apuração dos fatos, a reunião seguinte procurava discutir o que foi averiguado e percebido durante a visita e as entrevistas nos locais de maneira a esclarecer dúvidas quanto à confirmação ou não de assédio moral e como se deveria proceder, caso a denúncia fosse válida. Dessa forma, visava-se capacitar os membros da CS no sentido de auxiliá-los na condução de entrevistas, investigação, mediação, encaminhamentos e recomendações posteriores fornecidas ao denunciado e ao denunciante.

Durante o processo de capacitação, as queixas eram trazidas pelos próprios membros da CS, que percebiam possíveis indícios de assédio moral por meio de relatos advindos de servidores. Porém, com a consolidação da política, espera-se que a demanda venha espontaneamente sem a necessidade de relatos indiretos, uma vez que se garante a confidencialidade das informações.

Vale salientar que foi informado aos membros da CS que, em caso de conflito de interesses com relação à queixa, como, por exemplo, ter proximidade com o denunciante ou com o denunciado, ou trabalhar no mesmo setor, este deveria solicitar seu afastamento do caso, objetivando a ética durante a investigação.

Além das reuniões de treinamento, das visitas e das entrevistas, foi firmado um plano de ação, juntamente com os membros da CS, que previa a elaboração e a implantação de medidas de divulgação da existência da CS e seus objetivos, a realização de um evento para o lançamento do projeto e a apresentação do projeto e da CS nas unidades da secretaria. Dentre tais objetivos, somente as visitas às unidades ainda não foram realizadas.

\section{Análise das entrevistas}

As entrevistas com os membros da CS foram realizadas após a conclusão do treinamento. A seguir, são descritas as categorias principais observadas nos discursos dos membros da CS e as respectivas expressões-chave.

\section{Sentimentos negativos}

No discurso dos sujeitos entrevistados, percebe-se a coexistência de sentimentos positivos e negativos relacionados ao desenvolvimento do projeto, assim como à atuação eficiente por parte dos integrantes do grupo. Os sentimentos negativos relacio- nam-se a uma dificuldade em conciliar as atividades desempenhadas como membro da CS e como servidor público, havendo uma superposição de papéis que impede o andamento das atividades no tempo previsto. Guimarães (2009), revisando estudos sobre as transformações do trabalho dos servidores públicos frente à reestruturação produtiva, afirma que o trabalho em vários setores estatais foi intensificado e que as exigências impostas aos trabalhadores não foram acompanhadas de mudanças nas condições de trabalho, pelo contrário, as condições permanecem as mesmas ou piores, o que pode explicar, em parte, o sentimento de que o comprometimento pessoal não foi igual para todos os participantes devido à carga de trabalho a cumprir, como mostra o trecho de discurso a seguir:

Os pequenos problemas que a gente pôde encontrar nesse período [...] e que a coisa já tá bem resolvida, é essa questão do engajamento na equipe, da disponibilidade do tempo pra que a gente realmente dê uma importância maior ao trabalho, até porque você é absorvido em outras atividades e aí, no momento que chega pra gente sentar pra fazer esse trabalho, aí realmente alguns não dão prioridade, mas isso já foi conversado, a gente já se conscientizou que tem que ser priorizado, então eu acho que já está praticamente resolvido. (S1)

Certo ceticismo referente ao processo de investigação e ao trabalho da CS também surgiu como sentimento negativo, principalmente em decorrência da existência de relações interpessoais desiguais baseadas no grau de parentesco e na amizade e não apenas na competência dos trabalhadores:

O grupo permaneceu receoso durante o ano, pois nós conhecemos o grau de parentesco de cada um. O trabalho que dá em fazer uma investigação e no final ser arquivado por conta das características do corpo funcional da secretaria por causa do parentesco e amizade entre as pessoas. (S3)

Essa questão reflete um aspecto específico das instituições públicas onde os cargos e as benesses dependem dos relacionamentos mantidos dentro e fora da organização, como observou Tavares (2003) em seu estudo sobre uma instituição federal.

A falta de engajamento da equipe, a inexperiência por parte de alguns membros e o pouco tempo disponível para a CS foram fatores relatados como empecilhos para o desenvolvimento do trabalho.

\section{Sentimentos positivos}

Observam-se relatos semelhantes a respeito do comprometimento e do interesse do grupo em favorecer a prevenção e o combate a casos de assédio moral nas unidades da secretaria, propiciando melhores condições de trabalho aos funcionários, além de um consenso quanto ao bom relacio- 
namento e à integração entre os membros, como revelam as falas abaixo:

É um grupo de pessoas de muita responsabilidade, muita ética. Então é um grupo com comprometimento para que a comissão dê certo, para que o trabalho seja desenvolvido pra que a gente possa atingir a meta que a secretaria pretende. (S1)

Eu acho que isso é unânime, todos querem que, se realmente existir esse tipo de ato, a gente [...] quer que a coisa seja corrigida. E se for detectado alguma irregularidade em relação ao bom funcionamento, realmente a gente vai em busca para que a coisa seja resolvida. (S1)

Na verdade, [...] eu diria que existe um compromisso da comissão, [...] é que vai levar a frente para que possa excluir do meio da administração aquelas pessoas que não se conscientizaram o quanto o assédio moral faz mal e atrapalha o bom desempenho de cada um. (S4)

\section{Atuação da chefia}

A atuação da chefia foi relatada como um fator que pode proporcionar um ambiente de trabalho saudável, caso contemple o funcionário de maneira mais humana, como uma pessoa que atua com uma população de alto risco, procurando dialogar com ele a respeito de seu desempenho no trabalho e suas atitudes e orientando-o quando necessário, antes de se precipitar e tomar alguma decisão que possa causar sofrimento psíquico no servidor, como uma possível transferência. O trecho a seguir expressa a opinião de como a chefia deve agir:

[...] antes que o chefe se precipite a fazer uma avaliação apressada do funcionário, ele pondere, com mais tranquilidade, todo esse aspecto de desempenho dele, ele como pessoa, passe a conversar mais com o funcionário. (S1)

Nota-se aqui a importância dada à forma de liderança dos gerentes na ocorrência do assédio. Ayoko e Callan (2010) apontam que o estilo de liderança pode ser um fator "gatilho" na ocorrência do assédio, mostrando que líderes mais comunicativos e emocionalmente envolvidos com os subordinados levam a uma menor incidência de assédio moral no trabalho. Assim também Baillien et al. (2011) encontraram relações negativas entre a ocorrência de assédio e um estilo de liderança voltado para resolução dos problemas quando comparado a estilos autoritários e de esquiva dos problemas.

\section{Relação funcionários e população atendida}

Durante as entrevistas, o relacionamento entre os servidores públicos e a população atendida pela secretaria foi mencionado como um aspecto do trabalho dos funcionários que precisa ser analisado e investigado, visto que eles lidam com uma população em situação de vulnerabilidade social ou em situação de risco pessoal e social, o que gera, às ve- zes, uma sensação de impotência e falta de preparo para atender as demandas existentes e amenizar os conflitos emergentes. É preciso, então, favorecer melhores condições de trabalho, evitando os confrontos servidores-usuários, a fim de diminuir os conflitos que possam ocorrer entre chefia e subordinado e entre subordinados, visto que o ambiente de trabalho é permeado pelas dificuldades provenientes da população atendida. Nesse contexto, foi mencionada a necessidade de funcionários capacitados para atuar com os usuários. Como os funcionários podem prestar um serviço mais eficaz e humano se eles próprios não são assistidos de forma adequada? Se o ambiente de trabalho não favorece condições mínimas de saúde e bem-estar? A fala a seguir demonstra a importância de um bom relacionamento entre os servidores e os usuários:

[...] nós convivemos com pessoas que são altamente conflituosas, a gente não pode esquecer que a população é de alto risco, a secretaria é responsável por duas coisas: a proteção especial e a capacitação. (S5)

A existência de conflitos de qualquer ordem no ambiente de trabalho tem sido apontada como um dos precursores do assédio (BAILLIEN; DE WITTE, 2009; BULUTLAR; ÖZ, 2008) e também como um mediador de sua ocorrência (BAILLIEN et al., 2011). O interessante aqui é a escalada dos conflitos externos, da população atendida, para os conflitos internos.

\section{Atitude do funcionário}

Não somente a atuação da chefia foi citada como um aspecto que deve ser modificado a fim de garantir um ambiente de trabalho que seja concomitantemente saudável e produtivo. A atitude adotada pelo funcionário tanto com seu superior, quanto com outros funcionários foi apontada como um fator que pode favorecer ou prejudicar as atividades desempenhadas nas unidades. Na opinião dos entrevistados, é necessário que o servidor também pondere e dialogue com seu chefe ou colega antes de julgá-los, criticá-los ou agredi-los, como mostra este trecho: "Vai haver uma maior reflexão do chefe pra tomar alguma decisão e até mesmo o funcionário antes de fazer qualquer crítica ao chefe ou ao colega” (S1).

\section{Opinióes sobre o que é assédio moral no trabalho}

Embora os membros da CS sejam unânimes quanto à importância de ter tido uma discussão teórica sobre os conceitos e as implicações relacionadas ao assédio moral durante a capacitação, eles afirmam que o grau de conhecimento adquirido é insuficiente para lidar com as demandas, sendo necessário haver uma contínua articulação entre teoria e prática, como podemos observar nas seguintes falas: 
O aspecto importante é a gente tentar entender o assédio moral dentre as várias correntes existentes, fazer um confronto de ideias entre os autores, é muito ruim ficarmos em uma discussão linear sem ver as inúmeras faces, a gente deveria tentar ver isso ai. (S5)

Até que ponto a teoria que nós estamos estudando vai dar conta se existe ou não assédio moral? (S5)

Aquilo que a gente fez foi só pra teoria, tem que ser realmente praticado. (S2)

Ficou evidente que, pelo menos para um dos entrevistados, havia a necessidade de rever e confrontar os conceitos de assédio moral. Observou-se, durante o treinamento, que os representantes dos trabalhadores adotavam um conceito mais abrangente de assédio moral, congruente com o que hoje se discute como sendo assédio organizacional. Para Soboll (2008), assédio organizacional é um processo no qual a violência está inserida nos aparatos, nas estruturas e nas políticas organizacionais ou gerenciais, que são abusivas e inadequadas. Além disso, as más condições de trabalho eram comumente relatadas como forma de assédio, embora a literatura não considere a condição de trabalho em si como um ato de assédio (HIRIGOYEN, 2002). Dessa forma, percebe-se que, apesar de se buscar adotar um conceito único para o assédio, divergências podem surgir a partir dos pressupostos e dos interesses individuais e coletivos dos envolvidos.

\section{Atuação da comissão setorial}

As opiniões referentes à atuação da CS se dividiram em pelo menos quatro conceitos distintos. O primeiro deles se relaciona à opinião de que a CS funciona com o objetivo de trazer harmonia e orientar os funcionários a como proceder diante de uma agressão ou a como agir de maneira a evitar situações de conflito entre chefe e subordinado, como expressam as seguintes falas:

O que eu julgo mais importante nesse projeto para o bom desempenho do trabalho é em relação que chefia e subordinado tenham a consciência do respeito mútuo e até evita que o chefe ou subordinado tome atitudes precipitadas. (S1)

O segundo diz respeito a conhecer os conflitos existentes na secretaria, prevenir casos de assédio moral e promover um trabalho mais eficiente:

A importância é a gente tentar conhecer bem todos os conflitos existentes dentro da própria secretaria, nós trabalhamos com uma população de alto risco. (S5)

A gente sabe que a secretaria tem algumas questões de assédio moral, se a gente identificar, dar um encaminhamento para que se resolva essa situação para que não venha a ser repetitivo, então é claro que a gente vai melhorar mil vezes o trabalho. (S5)

O terceiro conceito remete à questão da concretização da investigação, enfatizando a CS como aque- la que vai propiciar a aplicação de uma punição ao assediador, o que não corresponde exatamente aos objetivos do trabalho da CS, pois sua atuação permite somente a investigação, a mediação e o acompanhamento dos casos denunciados. No entanto, a procedência de uma queixa, após a investigação pela CS, pode, de fato, quando do encaminhamento do caso para abertura de processo administrativo ou judicial, levar à punição do assediador.

Que se receba a denúncia, que se existe o assédio que seja apurado, mas não é só apurado, que realmente não fique só na verificação, se for comprovado o assédio, realmente aplicar o que a lei determina, tem que ser aplicada à pessoa que cometeu o assédio. (S2)

$\mathrm{O}$ último aspecto refere-se à necessidade da CS em divulgar o trabalho de prevenção e combate que está sendo realizado para que os funcionários tanto tenham conhecimento sobre o que é assédio moral, como saibam da existência de um grupo de pessoas a quem podem recorrer ao serem assediados ou ao observarem uma situação de assédio.

O grau de conhecimento que a gente vai tendo. Dizer ao setor que eles não estão sós, mostrar que tem uma equipe que tem interesse em ajudá-los em caso de dificuldades. (S3)

Avançar na questão das visitas, conscientizar os colegas de trabalho de que esse trabalho é um trabalho sério e que a comissão realmente se comprometeu para que possa debelar toda essa questão de assédio moral dentro da secretaria, não só aqui, mas em toda a secretaria. (S4)

Noventa por cento das pessoas não sabem o que é o assédio moral, muitos são assediados quase que diariamente e não sabem o que é. Então falta mais uma divulgação ampla para explicar mesmo o que é o assédio e que a pessoa pode se defender do assédio através de processar quem tá assediando a pessoa. (S2)

Os quatro aspectos estão de acordo com os objetivos e procedimentos do projeto proposto e são os aspectos que aparecem em quase todas as propostas e recomendações para a eficiência desse tipo de intervenção (TASK FORCE ON THE PREVENTION OF WORKPLACE BULLYING, 2001; TEHRANI, 2007).

\section{Apoio da gestão}

O apoio da gestão foi bastante citado como um dos fatores que podem contribuir para a eficiência do trabalho da CS, cabendo ao secretário executivo e aos demais gestores a função de facilitar e incentivar o trabalho realizado, reconhecendo a relevância do projeto e auxiliando na sua divulgação.

Um dos fatores mais fortes que deixa a comissão mais à vontade para que faça o seu trabalho é essa liberdade, essa abertura que a direção nos deu. (S1)

Tem que ser mais divulgado, deve ter reuniões com a coordenadoria, diretoria esclarecendo e o compro- 
misso principal da direção, do secretário executivo, secretário adjunto, coordenador, diretor, conscientizando de que eles têm que ter o primeiro compromisso. (S4)

O trabalho da comissão depende também da direção superior, se a direção superior do órgão der importância e seriedade à comissão, ela vai render frutos. (S3)

\section{Ceticismo por parte do servidor público}

Dentre os fatores que podem diminuir ou inibir a eficiência do trabalho na comissão, os entrevistados se referiram a um ceticismo por parte do servidor público, uma vez que, para ocorrer os procedimentos de investigação, é imprescindível que o funcionário assediado apresente sua queixa e, para tanto, ele precisa acreditar que seus direitos serão assegurados. Os discursos abaixo revelam a preocupação dos membros da CS com a falta de confiança do servidor:

Na proporção que a própria comissão observar ou sentir que realmente esse trabalho não está tendo êxito, muita gente vai ficar desestimulado. [...] Então eu acho que na hora que existir uma punição de alguns diretores, eu acho que o servidor vai ter mais credibilidade nesse trabalho e o próprio governo teria um resultado mais eficiente. (S4)

Porque o que existe no serviço público, sempre eu tenho dito em reunióes e vou dizer sempre se for preciso, é que o servidor público, ele não acredita, quando ele fala a verdade, ele pode ser prejudicado, ele pode ser mal visto pelo diretor, pelo coordenador, pela direção da secretaria ou de autarquia ou fundação. (S4)

Eu acho que as pessoas ficam mais inibidas, eles podem comentar, mas na hora de oficializar há um certo receio. Então é difícil para comissão identificar sem que essa coisa chegue realmente para comissão. (S1)

\section{Receio da CS em realizar a investigação}

Percebe-se no discurso de alguns dos entrevistados receio em realizar os procedimentos de investigação, tanto por acreditarem que ainda precisam de mais treinamento para avaliar os casos de assédio moral e elaborarem o parecer, como por se preocuparem com as repercussões que podem ocorrer em suas relações interpessoais no trabalho ao constatarem um caso de assédio moral:

O processo em si, a gente tem receio de todo o processo, de investigar, mediar, apurar os dados. Não se sente preparado. (S3)

[...] enquanto de um lado eu fico feliz em poder colaborar pra harmonia, no mesmo instante eu posso me deparar com alguma situação que a gente vai ter que tomar atitudes e que se, na verdade, for concretizado que existe o assédio ou de um ou de outro, que a gente vai ter que seguir para apurar e ver de quem está com a culpa realmente e ter que seguir em frente até que seja apurado e vê a legalidade de todo o processo, então assim, essa parte eu fico um pouco triste, mas a gente vai ter que chegar lá e realizar esse trabalho. (S1)

\section{Espaço físico}

Outro ponto relatado nas entrevistas como um problema ainda não resolvido no grupo refere-se à falta de um espaço físico para o desempenho das atividades sob a responsabilidade da comissão, o que dificulta a eficiência do processo de investigação, pois onde será realizado o recebimento da queixa, a elaboração do parecer e a mediação? Como confiar em uma CS que não possui seu próprio espaço para atuar? A falta de espaço físico pode diminuir a credibilidade do servidor na CS, já que corresponde a um indício de que o gestor não reconhece a importância do projeto: "Falta de espaço para termos as reuniões, fazermos as análises. Parece uma comissão artificial, tem os nomes das pessoas, mas onde funciona?" (S5).

\section{Mudança de governo}

A mudança de governo também foi apresentada como um aspecto que pode paralisar ou prejudicar o funcionamento da CS, tanto por ela necessitar do incentivo do secretário para dar continuidade às atividades previstas no Manual, quanto pelas possíveis modificações no corpo funcional, o que pode acarretar um incentivo menor dependendo de quem está ocupando a direção. Além disso, há uma dúvida constante do servidor público em confiar nas atividades de uma CS que depende do reconhecimento dos gestores, os quais podem ser substituídos em outro governo, conforme conjectura um dos entrevistados: "Será que eu denunciando, no outro governo eu vou ser discriminado? Será que não vai acontecer assédio moral comigo?” (S4).

Pires e Macêdo (2006) pontuam a descontinuidade e a ingerência política como características da cultura organizacional das instituições públicas, mostrando ser esse um fato gerador de instabilidade e insegurança entre os servidores. Assim, parece natural o medo de atuar como membro de uma comissão instaurada para investigar conflitos e situações de assédio e ter de tomar uma posição, pois, embora seus empregos sejam estáveis, há sempre a possibilidade de represálias quando da mudança de governo e de eles próprios serem assediados no futuro.

\section{Funcionamento do grupo}

Ao serem indagados sobre o funcionamento do grupo, os entrevistados apontaram a capacitação realizada como um fator válido para aprofundar seus conhecimentos e para viabilizar a concretização do projeto: "As reuniões funcionam bem, a capacitação, enquanto ela estava existindo, também funciona bem [...]” (S5).

Apesar de afirmarem o bom funcionamento do grupo, alguns membros da CS, durante os trabalhos, apresentaram dificuldades e posições contraditórias 
quando da tomada de decisões. O fato da CS ser estruturada de forma bipartite, com representantes dos trabalhadores e da gerência, faz com que conflitos externos ou preexistentes acabem influenciando as discussões dentro da CS. Essas divergências foram expressas de forma velada nas entrevistas, principalmente pelos representantes dos trabalhadores, que externaram a preocupação de se ter um "objetivo comum" e a necessidade de se aprofundar essa questão.

\section{Discurso do sujeito coletivo}

Com base nas ideias centrais, foi elaborado o seguinte discurso do sujeito coletivo que, em poucas palavras, relata as opiniões sobre o trabalho da CS e, consequentemente, sobre o projeto:

\begin{abstract}
Eu acho que o grupo, como um todo, tem se preocupado em realizar o trabalho, pois nós queremos ajudar os funcionários, dar melhores condições de trabalho para eles, promover a harmonia entre chefe e subordinado e, ao investigarmos casos de assédio moral, nós estaremos contribuindo para que isso ocorra. Só que nem todos têm o mesmo comprometimento, alguns componentes estão muito ocupados em outras atividades, não se mostram tão disponíveis para atuar na comissão, não estão sempre presentes nas reuniões e não têm iniciativas para realizar as atividades sem o apoio das professoras. A gente também precisa de um maior reconhecimento do diretor e secretário, eles que têm que ter o primeiro compromisso e nos acompanhar mais de perto na implementação e divulgação do projeto, pois o servidor público já tem medo de ser prejudicado se realizar uma denúncia, ele geralmente não confia que seus direitos serão garantidos, imagine se não contarmos com o apoio do gestor? Embora a capacitação tenha nos ajudado bastante, pois não conhecíamos o que era assédio moral, eu ainda não me sinto totalmente preparado para realizar a investigação e sei que ainda precisamos avançar mais e divulgar o trabalho que está sendo feito pela comissão.
\end{abstract}

\section{Análise da implantação da CS}

O presente estudo permite não somente a avaliação de uma intervenção para a prevenção e o combate ao assédio moral em uma instituição pública, mas também a análise das relações sociais existentes no contexto estudado. Essas relações refletem a cultura organizacional desse tipo de instituição e as transformações do trabalho no funcionalismo, que vem se destacando pela aplicação de conceitos gerenciais oriundos da iniciativa privada sem levar em consideração que os objetivos das instituições públicas não se coadunam com os das privadas. Isto pode explicar, em parte, as considerações sobre a falta de tempo dos membros da CS para realizar o trabalho proposto, em vista da alta carga de trabalho, e os conflitos existentes entre servidores e usuários. Essas mesmas dificuldades apontadas nas entrevistas como obstáculos a um trabalho mais efetivo são decorrentes da cultura de trabalho e das mudanças organizacionais implantadas nas últimas décadas no funcionalismo e parecem estar, também, na base da ocorrência do assédio moral no trabalho, como indicam os estudos sobre os antecedentes do assédio (ARAÚJO, 2009; BAILLIEN; DE WITTE, 2009; BAILLIEN et al., 2011; BESWICK; GORE; PALFERMAN, 2006; EINARSEN, 2000; SALIN, 2003; SKOGSTAD; MATTHIESEN; EINARSEN, 2007; STOUTEN et al., 2011; TRIJUEQUE; MARINA, 2008).

As percepções dos membros da CS sobre o projeto de intervenção demonstraram que, apesar do interesse comum na questão do combate ao assédio, ainda há muitos aspectos a serem trabalhados para garantir a sua efetividade. A capacitação mostrou ser um meio viável para maior aprofundamento do tema, bem como permitiu confrontar valores, expectativas e necessidades de cada membro. Com isso, infere-se que o favorecimento da comunicação contribuiu para o amadurecimento do grupo e a formação de sua identidade, embora a coesão grupal ainda seja deficiente.

Por outro lado, as entrevistas revelaram a importância de realizar uma seleção minuciosa para determinar os membros que podem compor comissões com os objetivos propostos em outras instituições. É necessário averiguar a disponibilidade, a responsabilidade, o interesse e o relacionamento interpessoal de cada um, uma vez que a falta de iniciativa e o descompromisso podem ser obstáculos difíceis de transpor em uma intervenção desse tipo.

Verificou-se, após o treinamento, um maior discernimento acerca do que é ou não um caso de assédio moral por parte dos integrantes da CS, o que facilita a elaboração de pareceres congruentes com a realidade presente nas unidades da secretaria e, provavelmente, será um fator importante na concretização de processos administrativos e judiciais visando à punição dos assediadores.

Ademais, percebe-se a necessidade do apoio contundente dos gestores no fornecimento dos subsídios necessários para o funcionamento desse tipo de comissão e o sucesso na sua implantação. O comprometimento da gestão deve envolver a liberação dos funcionários para a realização dos compromissos, o auxílio na divulgação dos trabalhos da comissão e o fornecimento de espaço físico e materiais para o desenvolvimento dos trabalhos.

\section{Considerações finais}

O estudo sobre a formação de uma Comissão Setorial de Combate ao Assédio Moral realizada no âmbito de uma secretaria do estado do Ceará, durante o ano de 2010, visou fornecer subsídios para a pro- 
pagação do projeto em outros órgãos do estado, visto que, a partir das experiências obtidas e das entrevistas realizadas, foi possível observar aspectos positivos e deficiências que podem ocorrer no contexto de intervenção em um grupo constituído por representantes da administração pública e de servidores.

Assim, os pontos altos do processo que devem ser repetidos em outros órgãos e entidades são a discussão teórica do conceito de assédio moral e o treinamento nos procedimentos de investigação: apuração dos dados, realização das visitas às unidades e elaboração de pareceres com subsequente debate a respeito de sua veracidade. Especial atenção deve ser dada à constituição do grupo, ao trabalho sobre as relações interpessoais (comunicação, esclarecimento de objetivos e expectativas, definição de papéis etc.), com foco no funcionamento grupal, e ao apoio institucional ao projeto.

Entre as limitações, o fato de o projeto ainda estar em desenvolvimento contribuiu para restringir o escopo da pesquisa, na medida em que o estudo contemplou a experiência de formação de somente uma comissão setorial. Também a pesquisa focalizou a percepção avaliativa do grupo sobre o treinamento e seu próprio funcionamento, não sendo feita uma análise acerca da eficácia das ações atribuídas à CS, pois essa fase do projeto ainda não havia sido implementada no período da coleta de dados.

Em futuras investigações, é importante considerar a comparação dos resultados de implantação de várias CS e agregar dados objetivos para avaliação da eficácia das intervenções, tais como número de denúncias, casos de assédio confirmados, processos administrativos julgados, entre outros.

Apesar das dificuldades encontradas, considera-se que esse tipo de intervenção pode contribuir para a melhoria da saúde dos trabalhadores e para uma ação mais significativa na melhoria das condições de trabalho no serviço público do estado do Ceará e de outras instituições públicas, principalmente no que se refere à prevenção do assédio moral.

\section{Contribuições de autoria}

Câmara, R. de A.: participou das etapas de treinamento do grupo, das entrevistas, da análise das entrevistas e da elaboração do manuscrito. Maciel, R. H.: participou da elaboração do manual de procedimentos do projeto, do treinamento da comissão setorial estudada, da análise dos resultados desta pesquisa e da elaboração do manuscrito. Gonçalves, R. C.: participou da elaboração do manual de procedimentos do projeto, do treinamento da comissão setorial estudada e da elaboração do manuscrito.

\section{Referências}

AGERVOLD, M. Bullying at work: a discussion of definitions and prevalence, based on an empirical study. Scandinavian Journal of Psychology, v. 48, n. 2, p. 161-72, 2007. DOI: 10.1111/j.1467-9450.2007.00585.X

ALTMAN, B. A. Workplace bullying: application of Novak's (1998) Learning Theory and implications for training. Employee Responsibilities and Rights Journal, v. 22, n. 1, p. 21-32, 2009. doi: 10.1007/s10672-009-9121-7.

ARAÚJO, A. C. Assédio moral organizacional. Revista Jurídica In Verbis, v. 14, n. 25, p. 65-80, 2009.

AYOKO, O. B.; CALLAN, V. J. Teams' reactions to conflict and teams' task and social outcomes: the moderating role of transformational and emotional leadership. European Management Journal, v. 28, n. 3, p. 220-235, 2010. DOI: 10.1016/j.emj.2009.07.001.

BAILLIEN, E.; DE WITTE, H. Why is organizational change related to workplace Bullying? Role conflict and job insecurity as mediators. Economic and Industrial Democracy, v. 30, n. 3, p. 348-371, 2009. DOI: $10.1177 / 0143831 X 09336557$.
BAILLIEN, E. et al. The relationship between the work units' conflict management styles and bullying at work: moderation by conflict frequency. Economic and Industrial Democracy, v. 32, p. 401-419, 2011. DOI: 10.1177/0143831X10377929.

BARRETO, M. Assédio moral: suas ocorrências e consequências. Fortaleza: Sindicato dos Bancários do Ceará, 2003.

BATALHA, L. R. Assédio moral em face do servidor público. Buscalegis, UFSC, Lumen Juris [on-line], 2009. Disponível em: < http://www.buscalegis.ufsc.br/ arquivos/assedio moral em face do servidor publico. pdf $>$. Acesso em: 5 fev. 2010.

BESWICK, J., GORE, J., PALFERMAN, D. Bullying at work: a review of the literature. Health and Safety Laboratory Working Paper Series, 6/4, 2006. Disponível em: <www.hse.gov.uk/research/hsl_pdf/2006/hsl0630. pdf $>$. Acesso em: 28 jan. 2010.

BULUTLAR, F.; ÖZ, E. Ü. The effects of ethical climates on bullying behaviour in the workplace. 
Journal of Business Ethics, v. 86, n. 3, p. 273-295, 2008. doi: 10.1007/s10551-008-9847-4.

CARAN, V. C. S. et al. Assédio moral entre docentes de instituição pública de ensino superior do Brasil. Acta Paulista de Enfermagem, São Paulo, v. 23, n. 6, p. 737-744, 2010.

CEARÁ [Estado]. Lei n⿳ำ 15.036, de 18 de novembro de 2011. Dispõe sobre o assédio moral no âmbito da administração pública estadual e seu enfrentamento, visando a sua prevenção, repreensão e promoção da dignidade do agente público no ambiente de trabalho, e dá outras providências. Diário Oficial do Estado do Ceará, Fortaleza, CE, 25 nov. 2011. Disponível em: <http://www.al.ce.gov.br/legislativo/legislacao5/ leis2011/15036.htm >. Acesso em: 20 set. 2012.

. Secretaria de Planejamento e Gestão. Manual de prevenção e combate ao assédio moral na administração pública. Fortaleza: Seplag, 2010.

DUBLIN INSTITUTE OF TECHNOLOGY. Dignity at work: anti bullying \& harassment complaints and investigation procedures for the Dublin Institute of Technology. Dublin: Dublin Institute of Technology, 2007. Disponível em: <http:/www.dit.ie/media/ humanresources/documents/policiesprocedures/ Dignity\%20at\%20Work\%20Anti\%20Bullying\%20 \&\%20Harassment\%20Complaints\%20\&\%20 Investigation\%20Procedures\%20-\%20HRP018.pdf> . Acesso em: 21 set. 2012.

EINARSEN, S. Harassment and bullying at work A review of the scandinavian approach. Aggression and Violent Behavior, v. 5, n. 4, p. 379-401, 2000. DOI: 10.1016/S1359-1789(98)00043-3.

EINARSEN, S.; HOEL, H.; NOTELAERS, G. Measuring exposure to bullying and harassment at work: validity, factor structure and psychometric properties of the Negative Acts Questionnaire-Revised. Work \& Stress, v. 23, n. 1, p. 24-44, 2009.

GUIMARÃES, M. C. Transformações do trabalho e violência psicológica no serviço público brasileiro. Revista Brasileira de Saúde Ocupacional, v. 34, n. 120, p. 163-171, 2009.

HIRIGOYEN, M. Mal-estar no trabalho: redefinindo o assédio moral. Rio de Janeiro: Bertrand Brasil, 2002.

HOEL, H.; GIGA, S. I. Destructive interpersonal conflict in the workplace: the effectiveness of management interventions. Manchester: University of Manchester; British Occupational Health Research Foundation and Manchester Business School, 2006. Disponível em: <http://www.bohrf.org.uk/downloads/bullyrpt.pdf>. Acesso em: 10 set. 2012.

LEFEVRE, F; LEFEVRE, A. M. C. Curso teórico prático de introdução ao discurso do sujeito coletivo e ao Software Qualiquantisoft. São Paulo: Instituto de Pesquisa do Discurso do Sujeito Coletivo (IpDsc), 2011.

MACIEL, R. H.; GONÇALVES, R. C. Relatório da campanha educativa e pesquisa sobre assédio moral.
Relatório Interno. Fortaleza: Sindicato dos Empregados e Servidores Públicos do Estado do Ceará, 2007.

. Pesquisando o assédio moral: a questão do método e a validação do Negative Acts Questionnary (NAQ) para o Brasil. In: SOBOLL, L. A. P. (Org.). Assédio moral/organizacional: uma análise da organização do trabalho. São Paulo: Casa do Psicólogo, 2008, p. 167-185.

MEGLICH-SESPICO, P.; FALEY, R. H.; KNAPP, D. E. Relief and redress for targets of workplace bullying. Employee Responsibilities and Rights Journal, v. 19, n. 1, p. 31-43, 2007. DOI: 10.1007/s10672-006-9030-y.

ORGANIZAÇÃO PANAMERICANA DE SAÚDE. Política da OPAS em matéria de prevenção e resolução do assédio no local de trabalho. Brasília: OPAS, 2004.

PATE, J.; BEAUMONT, P. Bullying and harassment: a case of success? Employee Relations, v. 32, n. 2, p. 171183, 2010. DOI: 10.1108/01425451011010113.

PIRES, J. C. D. S.; MACÊDO, K. B. Cultura organizacional em organizações públicas no Brasil. Revista de Administração Pública, v. 40, n. 1, p. 81104, 2006. DOI:10.1590/S0034-76122006000100005

SALIN, D. Ways of explaining workplace bullying: a review of enabling, motivating and precipitating structures and processes in the work environment. Human Relations, v. 56, n. 10, p. 1213-1232, 2003.

SENNETT, R. A cultura do novo capitalismo. Rio de Janeiro: Record, 2006.

SKOGSTAD, A.; MATTHIESEN, S. B.; EINARSEN, S. Organizational changes: a precursor of bullying at work? International Journal of Organization Theory and Behavior, v. 10, n. 1, p. 58-94, 2007.

SOBOLL, L. A. P. Assédio moral/organizacional: uma análise da organização do trabalho. São Paulo: Casa do Psicólogo, 2008.

STOUTEN, J. et al. Discouraging bullying: the role of ethical leadership and its effects on the work environment. Journal of Business Ethics, v. 95, p. 1727, 2011. DOI: 10.1007/s10551-011-0797-x.

TASK FORCE ON THE PREVENTION OF WORKPLACE BULLYING. Dignity at work: the challenge of workplace bullying. Dublin: Health and Safety Authority, 2001. Disponivel em: <http:// www.djei.ie/publications/employment/2005/ bullyingtaskforce.pdf> . Acesso em: 20 jul. 2012.

TAVARES, D. S. O sofrimento no trabalho entre servidores públicos: uma análise psicossocial do contexto de trabalho em um Tribunal Judiciário Federal. 2003. 152 f. Dissertação (Mestrado em Saúde Ambiental)-Faculdade de Saúde Pública, Universidade de São Paulo, 2003.

TEHRANI, N. Bullying at work: beyond policies to a culture of respect. London: Chartered Institute of Personnel and Development Bullying Guide, 2007. Disponível em: <www.cipd.co.uk/default.cipd>. Acesso em: 28 jan. 2010. 
TRIJUEQUE, D. G.; MARINA, S. D. El acoso psicológico en el lugar de trabajo. Antecedentes organizacionales. Boletín de Psicología, n. 93, p. 7-20, 2008. Disponível em: <http://www.uv.es/seoane/ boletin/previos/N93-1.pdf>. Acesso em: 24 set. 2012. VERRY, J. F. Prevention and resolution of workplace bullying. In: CONFERENCE OF THE ASSOCIATION OF INDUSTRIAL RELATIONS ACADEMICS OF
AUSTRALIA AND NEW ZEALAND, 22., Feb. 6-8, 2008, Melbourne, Australia. Proceedings... Melbourne: AIRAANZ, 2008. [non-refereed paper]. Disponível em: <http://www.mngt.waikato.ac.nz/ departments/Strategy\%20and\%20Human\%20 Resource\%20Management/airaanz/proceedings/ melbourne2008/nonref/papers/J.F.\%20Verry.pdf>. Acesso em: 3 mar. 2010. 